\title{
Hacer la calle en dictadura. Memorias trans del terrorismo de estado en Uruguay (1973-1985)
}

\author{
Gonzalo Gutiérrez Nicola \\ Universidad de la República, Uruguay \\ gonzagut@gmail.com
}

\section{Resumen}

De 1973 a 1985 tuvo lugar en Uruguay una dictadura cívico-militar. Durante ese período muchas personas sufrieron las consecuencias de la violencia del régimen, como la persecución, el encarcelamiento, la tortura y el asesinato. Durante ese período las mujeres trans (travestis) fueron sujeto de persecución por parte de los agentes del régimen, que las consideraban una degradación moral y social, vidas no calificadas que había que contener y marginar dado que no encontraban lugar en su proyecto político y en gran medida constituían una amenaza para este. El presente artículo se propone dar cuenta de la violencia que sufrieron las mujeres trans en ese período. Se basa en testimonios de personas que realizaron trabajo sexual en calle durante la última dictadura uruguaya. El estudio sitúa esa violencia contra las mujeres trans como parte del terrorismo de Estado.

Palabras claves: mujeres trans, memorias, terrorismo de Estado, violencia estatal. 


\title{
Make the street in dictatorship Trans memories of state terrorism in Uruguay (1973-1985)
}

\begin{abstract}
From 1973 to 1985 a civic-military dictatorship took place in Uruguay. During that period many people suffered the consequences of the regime's violence, such as persecution, incarceration, torture and assassination. During that period, trans women were subject to persecution by the agents of the regime, who considered them a moral and social degradation, unqualified lives that had to be contained and marginalized since they could not find place in their political project and to a large extent they were a threat to it. This article aims to account for the violence suffered by trans women in that period. It is based on testimonies of people who performed sex work in the street during the last Uruguayan dictatorship. The study situates the violence of the State towars the trans women as part of the State terrorism.
\end{abstract}

Keywords: trans women, memories, State terrorism, State violence.

Fecha de recepción: 8 de octubre de 2019.

Fecha de aprobación: 9 de diciembre de 2019. 
El presente texto está dedicado a Analía Beltrán y con ella a todas las mujeres trans que sufrieron la violencia de la dictadura y fallecieron sin tener una reparación por parte del Estado

\section{Introducción}

Durante la última dictadura cívico-militar uruguaya $(1973-1985)^{1}$ la disidencia sexual fue objeto de persecución por parte de policías, militares y otros agentes del régimen. En un contexto de terrorismo de Estado en que se produjo un repliegue generalizado de la población al ámbito privado, muchas mujeres trans ${ }^{2}$-en aquel momento se autodenominaban travestis- debieron ocupar el espacio público para realizar trabajo sexual que se configuraba casi que en su única posibilidad de subsistencia. En esas situaciones eran detenidas arbitrariamente y trasladadas a comisarías y a otros centros de detención. Allí eran fichadas bajo la categoría pederasta pasivo y permanecían recluidas por períodos de 24 horas hasta quince días y más. Diversos testimonios de mujeres trans relatan haber sufrido abusos sexuales, maltratos y torturas como golpes, picana eléctrica ${ }^{3}$ y submarino ${ }^{4}$. Las detenciones no solamente se realizaban en situación de trabajo sexual, también se podían producir en cualquier situación en que se las encontrara en la vía pública, y a quienes ya estaban fichadas se las iba a buscar a sus domicilios a distintas horas para llevarlas detenidas. En muchas ocasiones, para ser liberadas se les exigía realizar trabajos forzados como lavar y barrer las comisarías. Los testimonios permiten dar cuenta de que no se trataba de "excesos" o "desbordes" en el marco del accionar represivo sino de una práctica deliberada por parte de agentes del régimen hacia ese sector de la población.

\footnotetext{
${ }^{1}$ El carácter cívico-militar de la dictadura uruguaya se debe a que esta "resultó ser un poder único-compartido entre civiles (políticos y tecnócratas) y militares, ejercido por medio de un sistema de órganos estatales diversificados, tanto legales como clandestinos, que configuran no tanto un poder monocrático sino el tipo de una 'dictadurainstitución', una forma de Estado y de Gobierno de la sociedad" (Rico, 2013:242).

${ }^{2}$ En este trabajo se habla de mujeres trans dado que es la categoría con que se identifican actualmente todas las personas entrevistadas. Esa categoría no fue utilizada durante la dictadura, su incorporación en Uruguay se produjo en el presente siglo. Todas las personas entrevistadas dijeron identificarse a sí mismas como travestis durante la dictadura. Si bien en esta investigación también se utiliza la categoría travesti, se decidió utilizar también mujeres trans para respetar la denominación actual de estas personas.

${ }^{3}$ La picana es un dispositivo que permite aplicar descargas eléctricas sobre el cuerpo.

${ }^{4}$ El submarino consiste en sumergir en agua la cabeza de la persona para evitar que respire; se puede realizar "en seco" utilizando en lugar de agua una funda plástica que imposibilite la respiración.
} 
El presente artículo se propone dar cuenta de la violencia que sufrieron las mujeres trans en ese período. Se basa en testimonios de personas que realizaron trabajo sexual en calle durante la última dictadura uruguaya. Esos testimonios fueron reunidos por el autor en el marco de un estudio etnográfico con mujeres trans cuyo trabajo de campo fue realizado en el año $2017^{5}$ (Gutiérrez Nicola, 2018).

\section{Antecedentes}

Los estudios sobre la forma en que los terrorismos de Estado han abordado las disidencias sexuales son escasos en la región. Para el caso de Argentina se pueden mencionar algunos artículos compilados por Jorge Luis Peralta y Rafael M. Mérida Jiménez (2015). En particular en el texto escrito por María Soledad Cutuli y Santiago Joaquín Insausti (2015) se desarrollan las bases de una "memoria marica" que encontró sus espacios de performances en los cabarets, en los corsos y en los teatros de revista. La persecución y violencia estatal hacia la disidencia sexual entre las décadas de 1940 y 1980 generó que muchas experiencias fueran ocultadas y silenciadas por las memorias oficiales -tampoco encontraron lugar en la "modernidad gay"- pero se mantuvieron y transmitieron de formas imperceptibles para el poder. Para ambos autores, la recuperación de esas memorias tiene hoy un sentido político.

En lo que respecta a la violencia estatal, se puede mencionar el libro compilado por Débora D’Antonio (2015) en el que se destaca el artículo de Santiago Joaquín Insausti donde se discute la hipótesis que supone un plan sistemático de persecución, tortura y desaparición de disidentes sexuales durante la última dictadura cívico-militar argentina (1976-1983) y se establece en cambio una continuidad en el accionar estatal sobre ese colectivo desde el primer gobierno de Perón (1946-1952) hasta principios de la década del noventa con la desarticulación de los edictos policiales (Insausti, 2015).

\footnotetext{
${ }^{5}$ Los testimonios fueron reunidos en el marco de la tesis de grado del autor que incluyó ocho entrevistas individuales y dos grupales con mujeres trans mayores de 50 años. Todas ellas realizaron trabajo sexual en la ciudad de Montevideo durante la dictadura (1973-1985) y se identificaban en aquél período como travestis y actualmente se identifican como mujeres trans. Muchas de ellas continúan realizando trabajo sexual, aunque no lo hacen en calle, sino que reciben clientes en sus domicilios. El trabajo de campo para la presente investigación tuvo lugar durante 2017 y coincidió en parte con el proceso de discusión de la Ley Integral para Personas Trans que incluye una acción reparatoria para las personas trans nacidas antes del 31 de diciembre de 1975 que fueron violentadas por agentes del Estado. Esa ley fue finalmente aprobada en octubre de 2018.
} 
Para el caso brasileño se puede mencionar el libro de James N. Green y Renan Quinalha (2014) que reúne textos de diversos autores sobre la represión a las disidencias sexuales en la última dictadura (1964-1985), las formas de resistencia y su conexión con las luchas por la memoria en el presente.

En el caso de Chile se ha publicado recientemente el artículo de Fernanda Carvajal (2019) que analiza las estrategias represivas y tecnologías biopolíticas dirigidas hacia la población LGBT durante la dictadura militar (1973-1990).

Para el caso uruguayo, el capítulo de Diego Sempol y Federico Graña (2011) publicado en el libro Las Laurencias. Violencia sexual y de género en el terrorismo de Estado uruguayo constituye un texto de referencia que reúne testimonios que permiten ubicar a la disidencia sexual como un sujeto de persecución sistemática por parte de la dictadura cívico-militar. Tras el golpe de Estado en 1973 se instaló por parte de los militares "una noción de orden que idealizó el Occidente cristiano e hizo centro en la familia heteropatriarcal" (Sempol y Graña, 2011:89). Los militares promovían un conjunto de valores que se pretendían "naturales" pero que reproducían la ideología y los roles de género tradicionales; los/as disidentes sexuales pasaron a ser construidos como una amenaza y fueron objeto de persecuciones, detenciones y distintas formas de abuso por parte del régimen.

En su libro De los baños a la calle sobre la historia del movimiento de la diversidad sexual Sempol incluye testimonios de homosexuales y mujeres trans que sufrieron represión durante la dictadura (2013:44-56).

En otro trabajo Sempol (2015) realizó un estudio comparativo de la represión a la disidencia sexual entre las dictaduras de Argentina y Uruguay, el rol de la Doctrina de la Seguridad Nacional y el surgimiento de las organizaciones LGBT. Y en un trabajo más reciente el mismo autor analiza la emergencia de las memorias trans en Uruguay en el contexto de discusión de la Ley Integral para Personas Trans (Sempol, 2019).

En un estudio sobre vejez e identidades disidentes Maia Calvo Núñez (2013) realiza entrevistas a personas trans, gays y lesbianas comprendidas en esa franja etaria. En los relatos surgen sus vivencias de la dictadura uruguaya y las distintas estrategias que debieron utilizar para poder 
sobrellevar ese período. De acuerdo a los testimonios, la discriminación y sobre todo la violencia estatal inevitablemente marcaron la trayectoria de estas personas para quienes "el autocontrol infligido durante toda su vida, las estrategias de sobrevivencia, la incapacidad de pensarse posibles es constitutiva de esta generación” (Calvo Núñez, 2013:158).

Por su parte, el trabajo de Valentina Gómez Sóñora (2016) se sitúa en torno al proceso de cambio de nombre y sexo en los documentos identificatorios. Si bien no es su tema central, en el texto se recogen algunos testimonios de mujeres trans sobre sus vivencias en el período de la dictadura, entre ellas el testimonio de Gloria Álvez que con 76 años es probablemente la mujer trans más veterana del país.

Otro trabajo que analiza vejez e identidades trans fue realizado por Romina Mauros (2017) donde parte del hecho de que muy pocas personas trans llegan a viejas en Uruguay. Para estas personas "el llegar a la vejez podría interpretarse como un acto de subversión, una determinada rebeldía en contra de un sistema político, cultural y social que las oprime, discrimina y excluye" (Mauros, 2017:44). La autora destaca que la violencia sufrida durante la dictadura marcó profundamente las trayectorias vitales de las mujeres trans.

En otro texto Calvo Núñez (2017) recupera relatos de varones gays, mujeres lesbianas y mujeres trans sobre sus experiencias vitales desde la dictadura uruguaya en adelante, con el propósito de entender los mismos en relación a los cambios del contexto socio-histórico que atravesó el país desde ese período hasta la actualidad.

\section{La dictadura cívico-militar uruguaya}

La última dictadura cívico-militar en Uruguay se extendió desde junio de 1973 hasta marzo de 1985. La crisis política, social y económica en que estaba inmerso el país fue utilizada como pretexto para el golpe, aunque el comienzo de esa crisis se sitúa más de una década antes con el agotamiento del estado de bienestar del modelo batllista.

Durante la década del sesenta las organizaciones de izquierda comenzaron a cobrar un mayor protagonismo en la vida política del país, principalmente debido al fracaso de los gobiernos encabezados por los partidos tradicionales (Partido Colorado y Partido Nacional) y su incapacidad en promover alternativas para salir de la situación de crisis. En ese período se 
incrementaron las huelgas y movilizaciones sindicales y estudiantiles. En ese contexto algunas organizaciones de izquierda optaron por la lucha armada -entre ellas el Movimiento de Liberación Nacional - Tupamaros (MLN) que impulsó su accionar a partir de la táctica de la guerrilla urbana- en tanto otras organizaciones mantuvieron su accionar en el marco de la legalidad.

A partir de 1968 el gobierno llevó adelante un ajuste severo en la política económica que implicó la congelación de precios y salarios; y se impulsó una respuesta represiva frente a las acciones del MLN y al aumento de la protesta social. De este modo se vio incrementada la conflictividad y la violencia política condujo a "una secuela de civiles muertos y heridos que en el país no ocurría desde la última guerra civil de 1904" (Caetano, 2016:55).

En las elecciones de 1971 triunfó el Partido Colorado que llevó a la presidencia a Juan María Bordaberry, en cuyo gobierno se produjo la derrota militar del MLN en 1972 y se terminaron de consolidar las bases para el golpe cívico-militar que se produjo en 1973. Los militares se presentaban como quienes venían a restaurar el orden perdido. Desde su óptica, el sistema político había sido incapaz de lidiar con el "problema de la subversión"; un problema que trascendía ampliamente el accionar de los grupos guerrilleros - entre los cuales el MLN era el más importante numéricamente pero no el único- y que abarcaba también a sectores de la izquierda política y social que desplegaban su accionar en el marco de la legalidad, como la intervención en sindicatos y gremios estudiantiles.

A su vez, y también desde la óptica de los militares, el sistema político no sólo no había estado a la altura de las circunstancias en la lucha contra ese "problema", también había sido responsable de llevar adelante acciones que habían conducido al país a la debacle económica, política y social. De este modo, la irrupción de los militares en la escena política no fue sólo para acabar con la guerrilla sino - principalmente- para restaurar el orden perdido. Su discurso en gran medida se sustentaba en que las Fuerzas Armadas (FF.AA.) se ubicaban por fuera del campo político, y por tanto no estaban "contaminadas" por éste. Ese supuesto carácter apolítico de las FF.AA. ha sentado las bases para que se piensen y se presenten como garantes de los principios, valores y normas constituyentes de la "esencia nacional” (Micieli y Pelazas, 2017:41-42). 
La dictadura llevó adelante, a través del autoritarismo y la violencia, las políticas que hasta ese entonces la clase dominante no había podido imponer por la oposición de sectores sociales y políticos; y lejos de solucionar los problemas del país los agravó en todos los niveles, conduciéndolo a uno de los períodos más críticos de su historia.

En 1974 el Consejo de Estado aprobó una nueva Ley Orgánica Militar que incluyó las concepciones de seguridad y defensa nacional en sintonía con la Doctrina de la Seguridad Nacional que establecía el marco común a las dictaduras latinoamericanas de la década del 70 en el contexto de la Guerra Fría. Allí se definía al comunismo como el enemigo principal que enfrentaban los países, un enemigo que se expresaba a través de la subversión y al que las FF.AA. debían enfrentar en distintos frentes.

En todo el período se vivió bajo el terrorismo de Estado: la actividad política fue prohibida, fueron encarcelados referentes de sectores políticos y sindicales. Se llevó adelante un plan sistemático que incluyó la vigilancia y seguimiento de personas, detenciones, torturas, secuestros $\mathrm{y}$ desapariciones. Ese plan fue instrumentado por el régimen que puso funcionarios y recursos materiales y logísticos que tenía a su disposición e incorporó otros que estaban "por fuera" de su estructura como los centros clandestinos de detención y la utilización de civiles que colaboraron.

En el plano social se estableció un régimen de control en varios niveles donde "la censura en la información, la prohibición de toda actividad política y sindical, la represión física y el control de las actividades colectivas" (Greising et al., 2011:91) configuraron lo que algunos autores han denominado como cultura del miedo.

De este modo, se consolidó un clima que atravesó a toda la sociedad y no solo a quienes eran perseguidos por motivos políticos. El alcance de ese clima también "penetró en el ámbito de la vida privada, de lo cotidiano de las interacciones sociales o familiares, pretendiendo atomizar el tejido de las relaciones sociales en su conjunto" (Serpaj, 1989).

La construcción del "enemigo interno" fue un componente central de la estrategia llevada adelante por las FF.AA. para hacerse del poder, ganarse la adhesión de la ciudadanía y obtener legitimidad para consolidar su proyecto político. Esa "amenaza" podía encontrarse en cualquier lado, y así se justificaba cualquier intervención, con los medios y las formas que el régimen 
entendiese pertinentes. La vinculación entre una persona y la "subversión" era una atribución que el régimen se autoasignaba, y que se basaba en criterios arbitrarios que solo operaban ante sí y para sí.

Las dictaduras de la década del 70 tuvieron diferencias importantes respecto a las que se habían producido en la región anteriormente durante el siglo XX. Las FF.AA. que asaltaron el poder a partir de los 70 habían sido adoctrinadas en la lucha antiterrorista, concebían esa lucha como una "guerra interna" y los métodos que utilizaban eran acordes con ello. El terrorismo de Estado no sólo fue un instrumento de represión de grupos políticos y de control social, también cumplió un rol de redisciplinamiento de la sociedad.

\section{Las disidencias sexuales}

En materia homoerótica, durante la segunda mitad del siglo XX prevaleció en Uruguay el denominado modelo latino -también conocido como modelo "loca-chongo" o "maricachongo"- que reproduce los esquemas clasificatorios que oponen lo masculino y lo femenino. El chongo es un varón que sin renunciar al prototipo masculino se relaciona sexualmente con maricas, es decir homosexuales afeminados (Perlongher, 2018:39). En esa relación, el hombre es el que penetra a las mujeres o a otros hombres "feminizados" (locas o maricas). La reproducción de la jerarquía hombre-mujer en la relación homoerótica hace que quien asume el rol activo (chongo o bufarrón $)^{6}$ no sea considerado homosexual y en gran medida quede por fuera del estigma asociado a esta (Sempol, 2018:224) ${ }^{7}$.

En ese contexto donde la orientación sexual y la identidad de género se superponían, las travestis eran consideradas homosexuales, o en todo caso una especificidad dentro de la homosexualidad antes que una población en sí misma. Esto se reforzaba en el hecho de que en un ambiente de alta discriminación social hacia las sexualidades disidentes muchas se vestían como varones durante el día y solo se travestían en la noche para trabajar. De todos modos, la marica y la travesti tenían mayor visibilidad en gran medida por los estereotipos instalados desde los medios de

\footnotetext{
${ }^{6}$ Términos como loca, marica, chongo y bufarrón aún se utilizan en Uruguay, aunque en algunos casos hayan tenido desplazamientos de sentido.

${ }^{7}$ Para el caso uruguayo, un estudio sobre los distintos sentidos atribuidos a la homosexualidad en la segunda mitad del siglo XX y la discriminación socialmente legitimada hacia esa población se puede leer en Sempol (2018).
} 
comunicación y en espectáculos públicos como el carnaval ${ }^{8}$. Incluso las propias travestis concebían a los homosexuales como personas que no tenían el coraje suficiente de travestirse y salir a la calle.

Las expresiones públicas de las sexualidades disidentes pasaban principalmente por las zonas de levante homosexual que fueron cambiando con el tiempo pero que por lo general se concentraban en zonas céntricas de Montevideo o en espacios con mucha circulación de personas que favorecían el encuentro entre varones homosexuales y habilitaban la posibilidad de mostrar y disimular la orientación sexual a los transeúntes. Al mismo tiempo se fueron consolidando zonas de trabajo sexual en calle, donde eran las travestis quienes tenían mayor presencia.

Ambas expresiones fueron objeto de fuerte discriminación social y de persecución durante la dictadura e incluso desde períodos anteriores ${ }^{9}$, pero en tanto los homosexuales que acudían a las zonas de levante se replegaron al ámbito privado y cambiaron sus lugares de encuentro, quienes subsistían del trabajo sexual debieron encontrar formas de seguir desarrollando la actividad en el espacio público.

Si bien durante la década del 60 se producían detenciones en el comercio sexual callejero -la unidad policial encargada solía ser la División de Orden Público- los períodos de detención no eran mayores de 24 horas. Luego del golpe de Estado en 1973 las detenciones aumentaron y lo hicieron por más tiempo -llegando a ser de una semana o quince días- en tanto los maltratos y torturas se hicieron una práctica cotidiana (Sempol, 2013:51) ${ }^{10}$.

\section{La persecución a las travestis}

"En aquella época éramos nada, no éramos personas"

\footnotetext{
${ }^{8} \mathrm{Al}$ igual que en el caso argentino estudiado por Cutuli e Insausti (2015), en el carnaval uruguayo también se habilitaron espacios para la aparición pública de travestis, principalmente en comparsas y en desfiles barriales. No obstante, desde el carnaval también se contribuyó a la estigmatización de las sexualidades disidentes. Algunos casos de letras de murgas se consignan en Sempol (2018). Durante la dictadura, la censura a la crítica política motivó que el humor en torno a la sexualidad sea un tema elegido por muchas murgas para sus repertorios y era frecuente que aparecieran personajes que estereotipaban a las travestis con la finalidad de hacer reír al público.

${ }^{9}$ Las formas de persecución policial en los circuitos de levante exceden el alcance del presente artículo.

${ }^{10}$ Es importante señalar que ni durante la dictadura ni en períodos anteriores existieron en Uruguay leyes o normativas que de forma explícita criminalicen a las disidencias sexuales.
} 
Testimonio de Krisse Cardozo en Trans-Ur, capitulo 29, diciembre $2015^{11}$

La dictadura se propuso "refundar" el país y para ello llevó adelante un proceso de "reconstrucción nacional" que tuvo como base a la Doctrina de la Seguridad Nacional entremezclada con valoraciones morales que "buscaban preservar la nación, la familia heteropatriarcal y a los jóvenes de 'desviaciones sexuales' y 'corrupciones morales' que permitieran anidar la subversión” (Sempol, 2013:45).

El objetivo era homogeneizar a la ciudadanía, haciendo énfasis en la juventud, a quien había que inculcar determinados valores -identidad nacional, disciplina, abnegación, sentimiento patriótico, respeto por la autoridad, roles de género, entre otros- que la forjaran como activa defensora del régimen e impermeable a la propagación de las ideas de izquierda.

Desde esta visión, quienes no estaban en sintonía con los valores que promovía esta "cruzada" eran construidos como un elemento de riesgo al que había que combatir y/o controlar para que su influencia no se propagara entre la juventud "sana". La valoración de la disidencia sexual por parte del régimen debe ser considerada desde esta perspectiva, que la constituyó en un factor de riesgo para su proyecto político y para su base de sustento que era un "orden natural" centrado en la familia heteropatriarcal.

Caetano y Rilla (2017) sostienen que los militares no lograron formular un proyecto fundacional de país por lo que prefieren denominar al período comprendido entre 1976 y 1980 como "ensayo fundacional". De todos modos, al menos en algunos aspectos ese "ensayo" no sólo se logró concebir sino también instrumentar su propósito. Por ejemplo, se logró construir una nueva definición del concepto de persona, que en cualquier régimen constituye un componente básico y elemental a partir del cual concebir e instrumentar su proyecto.

La dictadura trazó una nueva demarcación a partir de la cual considerar quién era persona y quién quedaba al margen de esa adscripción. Si el comunista y el tupamaro representaban la antítesis del ciudadano ideal promovido por el proyecto dictatorial, las travestis representaban el negativo

\footnotetext{
${ }^{11}$ Trans-Ur es un proyecto llevado adelante por la activista trans Sofía Saunier que reúne entrevistas de carácter biográfico a personas trans. Todos los capítulos de Trans-Ur están disponibles en el canal de Youtube de la autora: https://www.youtube.com/channel/UChL1kuCbfrvUI3YaXiedDog
} 
de su dimensión moral-natural-sanitaria. Para un régimen que promovía activamente una forma de corporalidad esencialista y homogeneizante, donde ocupaba un lugar central el cultivo del físico, pero también la presentación del cuerpo -uniformes en escuelas y en liceos, uniformes para obreros y obreras, obsesión por los desfiles estudiantiles, control de cortes de pelo y vestimenta en la entrada de los centros educativos- en los cuerpos travestidos, en esa lógica de alineación cuerpo-mente, no podía sino caber más que una mente inmoral, que nada positivo podía aportar a una sociedad que se estaba "sanando" de sus múltiples desvíos.

Podemos suponer que para los represores las travestis no configuraban un sector "subversivo" en el sentido que ellos le atribuían a ese término. "Subversión" y "sedición" eran términos que hacían referencia a sectores que militaban para instaurar el "comunismo" en el país. Esos sectores podían ser grupos políticos (principalmente grupos de izquierda), pero también sindicatos, gremios estudiantiles y otras organizaciones vinculadas a temas sociales y culturales. La construcción social de la "subversión" era lo suficientemente amplia para abarcar a distintos grupos y personas según las necesidades de la coyuntura.

Si bien su connotación era "lo suficientemente difusa como para atribuir el rasgo de enemigo a todo aquél que no fuera idéntico" (Micieli \& Pelazas, 2017:291), la etiqueta de "subversivo" no era común que fuera atribuida a las travestis, lo que no implica que no hayan sido objeto de persecución y represión por parte del régimen. Estas personas tampoco eran consideradas delincuentes, no tenían derecho a ser juzgadas ni procesadas, ni a tener la condición de "presas" o "privadas de libertad" que se adquiría a través de un proceso al que no podían acceder.

Pero esos cuerpos, que incluso se atrevían a ocupar el espacio público, no sólo le enrostraban al régimen que su proyecto aún estaba incompleto, sino también que era inútil. Constituían una amenaza no por lo que hicieran sino por lo que eran, y por ello debían ser perseguidas.

\section{Hacerse trans en Montevideo}

En la década del 70 muchas trans adolescentes y jóvenes, buscando un espacio donde vivir su identidad tras ser expulsadas de sus hogares o luego de mudarse a la capital Montevideo para escapar de la escasa privacidad y alta discriminación de las ciudades del interior del país, encontraban un lugar junto a otras mujeres trans, con quienes compartían la vivienda y eran 
introducidas por estas en el mundo trans/travesti: cómo vestirse, cómo maquillarse, las estrategias para feminizar el cuerpo, las formas de ganarse la vida, etc.

En esa época no cualquiera nos alquilaba una vivienda, aunque tuvieras plata, por eso teníamos que ir a vivir con otras o a una pensión que sabías que nos aceptaban (Entrevista a Dinorah).

María se vino del interior a vivir en lo de una cafetina". Ella fue quien la llevó a la parada "en Bulevar Artigas ${ }^{13}$ y Coquimbo (...) para no tener problemas con las de Martín Fierro ${ }^{14,}$. Como señalaron otras, venirse desde el interior a Montevideo era un paso importante no solo para poder vivir su identidad, también para poder vivir de los ingresos del trabajo sexual.

En Paysandú, con el cuento de los hippies, yo usaba el pelo largo... pero fue en Montevideo donde empecé a vestirme de mujer (Entrevista a María).

En esa época todo el mundo se empezó a venir a Montevideo [...] acá hacías plata. Nunca vi tantos penes como en Montevideo; de día, de noche, a cualquier hora (Entrevista a María).

Algunas hicieron referencia a un período gay o marica en sus vidas, más que nada relacionado con los procesos previos a asumirse como travestis y también a las escasas posibilidades de vivir esa identidad en sus localidades de origen.

Yo allá era mariquita, no sé cómo decirte; travesti me hice acá [en Montevideo] (Entrevista a Dinorah).

Allá en mi pueblo solo me travestí una vez, en carnaval. [Entrevista a Elisa]

Cuando vine yo era un 'gaycito' más, pero bastante afeminado; pero acá [en Montevideo] me empecé a travestir, quería vivir la libertad (Entrevista a Alejandra).

La "fama" de Bulevar Artigas era conocida en el interior y algunas lo veían como un lugar donde no sólo podrían ganarse la vida, también como un lugar donde podrían ser quienes querían ser, ya que "a 'avenida' ainda é o locus privilegiado de sociabilidade e de visibilidades das travestis" (Pelúcio, 2005:246).

\footnotetext{
${ }^{12}$ Una cafetina era una mujer trans, generalmente mayor, que podía alojar a otras mujeres trans en su casa a cambio de dinero. Además, podía cumplir un rol en introducir a las jóvenes en el trabajo sexual, conseguirles una paradalugar en la calle donde se exhiben para conseguir clientes-, el acceso a clientes, etc. y pedir un pago por esto y también por brindar seguridad. Algunas cafetinas también tenían conocimientos sobre modificaciones corporales como aplicar silicona en los senos.

${ }^{13}$ Bulevar Artigas es una avenida de la ciudad de Montevideo donde se desarrolla el trabajo sexual desde los años 1967-1968 hasta la actualidad (Sempol \& Graña, 2011:93).

${ }^{14} \mathrm{Se}$ refiere a las travestis que paraban en la esquina de Bulevar Artigas y Martín Fierro.
} 
Éramos unas de Fray Bentos, otras de Mercedes, otras de Paysandú [...] Todo el interior se venía para la capital. No nos toleraban en nuestros pueblos y nos veníamos a la capital buscando la famosa Bulevar (Entrevista a Dinorah).

Para algunas de ellas venir a Montevideo a hacer la calle era parte de "realizarse" en su identidad. La calle "es el lugar donde aprenden a ofrecer su identidad como espectáculo, donde pueden reconstruir su autoestima, donde sus deseos negados pueden cobrarse pequeñas venganzas" (Fernández, 2004:188).

\section{Hacer la calle}

Por lo general las mujeres trans eran introducidas al trabajo sexual a través de otra mujer trans que ya tenía experiencia. Era ésta quien les explicaba cómo hacer el trabajo, los códigos que se debían respetar para hacer la calle, los criterios de seguridad, y también era quien las llevaba a un lugar en donde trabajar. El ser introducidas en la parada por otras mujeres trans les daba legitimidad para ocupar ese espacio y esto solía tener una contraprestación en dinero. Había cafetinas que cobraban semanalmente por ocupar la plaza y brindar seguridad. Algunas incluso podían tener acuerdos con los policías a los que les entregaban dinero y estos podían tomar represalias en caso de que no se hicieran los pagos a la cafetina.

La parada era un lugar al que no era fácil acceder si no se tenían vínculos, sobre todo si se trataba de un lugar que ya era identificado por los clientes como una zona donde se podían encontrar travestis, con lo cual el arribo de más trabajadoras sexuales implicaba mayor competencia para las que ya estaban. Además de la circulación de clientes, las paradas podían tener otras ventajas como estar próximas a lugares más ocultos donde cambiarse, atender clientes o hacer las necesidades, y también contar con vías de salida para poder huir u ocultarse de la policía. Los jardines que daban al frente de algunas casas sobre Bulevar Artigas eran lugares muy usados para estos fines. En muchos casos, sus propietarios/as permitían la actividad de las travestis, pero se acordaba que el lugar debía mantenerse limpio y cuidado. Algunas entrevistadas recordaron casos de propietarios/as con quienes mantenían buen vínculo y que en ocasiones permitieron que ingresaran a sus casas para evitar ser detenidas.

Aunque existían conflictos con otras travestis, generalmente por el lugar en la esquina o por el acceso a clientes, muy pocas hicieron énfasis en eso y en cambio resaltaron la solidaridad que 
existía entre ellas. Si muchas veces se ha hecho referencia a ciertos niveles de competencia en el trabajo sexual en calle, los altos niveles de represión sumados a la distancia temporal pueden incidir en que se resalten los componentes de compañerismo y solidaridad.

A veces podías tener un problema en la calle, pero estando adentro en algún momento te cruzabas y ahí estábamos en la misma (Entrevista a Claudia).

Cuando estábamos en la celda, si escuchabas los tacos era una alegría. Sabías que era una de nosotras. Para mi era la alegría más grande en esos momentos (Entrevista a Dinorah).

Muchas de nosotras nos terminamos de conocer en los calabozos. Estábamos días adentro y ahí compartías historias, entonces te ibas conociendo con las otras (Entrevista a Paula).

Esa solidaridad se expresaba en el cuidado de las otras:

Si veías que venía la policía vos le avisabas a las de la otra esquina, o ellas te gritaban (Entrevista a Paula).

Cuando venían era el griterío: “¡la camioneta!”, “¡la camioneta!”. Se iba corriendo la voz. (Entrevista a Elisa).

Una vez me tomé un taxi por [la avenida] Propios y les iba avisando en las esquinas que atrás venía el camión de los milicos levantando gente (Entrevista a Dinorah).

Según varios relatos, el trabajo sexual les proporcionaba el dinero suficiente para alquilar una pensión o juntarse con otras trans y alquilar un apartamento y contar con lo básico para su subsistencia. Varias hicieron referencia a que el dinero en esa época les rendía mucho más:

La plata que se hacía en esa época rendía mucho más que ahora (Entrevista a Paula).

Yo no iba todos los días a trabajar, y aún así me daba para pagar el alquiler y tenía la heladera bien surtida (Entrevista a María).

No sé si las cosas eran más baratas o hacías mucha plata; creo más que las cosas eran más baratas y vos podías acceder a cosas que ahora no (Entrevista a María).

Dinorah estuvo un tiempo viviendo en la calle, pero el acceso a clientes que tenían más poder adquisitivo le permitió contar con ingresos para poder sobrellevar esa situación:

Yo vivía en Ciudad Vieja, cuando conseguíamos un cliente nos íbamos a una pensión en la calle Buenos Aires y lo hacíamos pagar al cliente por toda la noche, entonces ahí nos podíamos bañar bien y dormíamos (Entrevista a Dinorah).

En esa época venían muchos marineros, muchos alemanes [...] Una noche con un alemán de esos te daba para vivir quince días (Entrevista a Dinorah). 
Estar en la parada implicaba estar atenta a la circulación de autos con potenciales clientes y a los vehículos policiales y militares que recorrían la zona. Se daba una tensión entre mostrarse/ocultarse en función de quiénes circularan por la calle y por la vereda.

No podías bajar la guardia porque con los clientes también había que tener cuidado (Entrevista a Claudia).

Ni bien llegaba a la parada ya estaba viendo los lugares para rajar ${ }^{15}$ (Entrevista a Paula).

En un segundo mostrabas una teta y al otro te estabas sacando los tacos y a correr (Entrevista a Elisa).

Las reparticiones policiales y militares que las detenían eran muchas:

Mirá era Hurtos, Narcóticos, Orden Público, Brigada de Asaltos, fijate todas las reparticiones que nos llevaban detenidas. Y cuando no aparecían los "verdes" (militares) [...] Y después habían puesto el auto famoso aquél, el operativo Saturno... Era un auto particular que no lo podías descifrar y también te llevaba (Entrevista a Dinorah).

Vos al final no sabías quién era el que te llevaba, que Orden Público, que Hurtos y Rapiñas, ya no sabías quién era (Entrevista a Verónica).

\section{Los fichajes}

El fichaje constituyó un elemento clave del control que pretendía imponer el régimen sobre la ciudadanía. Su efecto iba más allá de lo que los represores hacían con esa información ya que periódicamente difundían por distintos medios listas con nombres de personas detenidas para incentivar la sanción social. Quienes estaban en la función pública eran ubicados en tres categorías: A, B y C. Muchos sectores del ámbito privado que apoyaban al régimen -o a veces por miedo o para obtener beneficios- se valieron de esos registros para dar señales de su compromiso y buena conducta. Por ejemplo, figurar como alguien vinculado de alguna manera a la "subversión" podía implicar ser expulsado del trabajo y no ser aceptado en las solicitudes de empleo.

La disidencia sexual no escapó a esto. Las categorías pederasta pasivo y pederasta activo eran las que se utilizaban en los registros policiales para identificar respectivamente a las travestis y a sus clientes. Varios testimonios dan cuenta de las implicancias de ser fichadas como pederastas pasivos:

${ }^{15}$ Correr. 
Una vez que te fichaban te iban a buscar donde estuvieras (Entrevista a Claudia).

Quedabas en manos de ellos, sabían dónde vivías, dónde encontrarte; una vez que te fichaban te cambiaba la vida (Entrevista a Mariana).

El fichaje limitaba las posibilidades de estas personas en varios niveles y su efecto terminaba siendo el inverso al que supuestamente se buscaba. Una vez fichada como pederasta pasivo las posibilidades de conseguir empleo se reducían y solo quedaba la alternativa del trabajo sexual. El fichaje les restringía las vías para una trayectoria de vida por fuera de éste.

Dinorah se vino de Fray Bentos en 1977 pero a diferencia de otras mujeres trans que llegaban a Montevideo para dedicarse al trabajo sexual, ella consiguió trabajo como cadete en una farmacia, "pero iba vestida como varón”. La experiencia duró muy poco, al mes la detuvieron en una razzia en la parada del ómnibus y por su apariencia afeminada quedó fichada como pederasta pasivo y perdió el empleo. Ese fichaje fue lo que la llevó a dejar de lado sus ilusiones de contar con un trabajo formal y pasó a dedicarse al trabajo sexual. Comenzó en la zona del Mercado Modelo donde también la detuvieron. Se quedó en situación de calle; estuvo un tiempo viviendo en el entorno de la plaza Independencia y trabajaba por esa zona. Ahí continuó un periplo de varias detenciones y situaciones de violencia.

Así como los judíos tenían un "coso" para nosotros era P.P. (Entrevista a Alejandra).

Alejandra se refiere a las estrellas de David que los nazis les colocaban a los judíos para identificarlos en los campos de concentración. Si bien el fichaje como pederasta pasivo no era una insignia que se colocaba en la ropa de la persona, de todos modos su "visibilidad" era muy alta en tanto la información no quedaba "durmiendo" en los archivos policiales esperando que alguien preguntara por ella sino que circulaba por distintos canales.

Yo vivía con mi hermana y mi cuñado que era milico del cuartel. Cuando me ficharon me tuve que ir porque mi cuñado me dijo que si llegan a enterarse que vivía con un puto lo echaban del cuartel. Entonces me tuve que ir (Entrevista a Estela).

Si bien el fichaje como pederasta pasivo se vivía como un problema serio, que en cierto sentido implicaba un antes y un después para la persona fichada, también para algunas esa gravedad estaba matizada por su inevitabilidad una vez que empezaban a hacer la calle o se asumían como travestis: 
Vos ya sabías que en algún momento te iban a fichar (Entrevista a Claudia)

Una vez que habías tomado la decisión de pararte en una esquina, sabías que en algún momento te iban a llevar; más tarde o más temprano te iba a pasar, y ahí quedabas fichada (Entrevista a Mariana).

Yo venía zafando, y un día caí, me agarraron y dije "bueno, cagué, me van a fichar" (Entrevista a Daniela).

El fichaje era un dispositivo reificante, establecía una etiqueta sobre alguien: se era tal cosa. Y esa atribución que el régimen hacía sobre determinados "tipos" de individuos con la finalidad de controlarlos (sean subversivos o pederastas pasivos) operaba como un despersonalizador/deshumanizador, quedaban fuera de la categoría de persona. El fichaje como pederasta pasivo configuraba una etiqueta de nuda vida, para el régimen pasan a ser vida superflua, excedentaria, "vida que no merece ser vivida" (Agamben, 2010).

No obstante, el fichaje también generaba un efecto inverso al que se proponía, llevaba a estas personas a tener que desarrollar nuevas estrategias, a encontrar formas individuales y colectivas para resistir, para escapar a los mecanismos de control, o para lidiar con estos cuando no podían evadirlos: a dormir en la azotea de la pensión para que no las encontraran, a mudarse, a cambiar la zona de trabajo.

\section{El rostro de la represión}

Verónica llegó a estar quince días detenida, la detuvieron siete días y la soltaron un día por la mañana; esa misma noche la detuvieron siete días más. La torturaron varias veces, le pusieron la capucha, la golpearon y le dieron picana. Le pidieron que diera nombres de $\operatorname{chorros}^{16}$.

Algunas decían cualquier cosa para que no las torturen más (Entrevista a Verónica).

Dinorah relata que cuando se producía algún hurto en la zona u otro incidente policial era común que las llevaran a ellas para interrogarlas:

Te preguntaban si fulano era tu marido, te preguntaban por gente que andaba robando. Si dabas un nombre esa vez te salvabas, pero después era peor porque te iban a buscar siempre. [...] Una vez me dijeron: "Si no entregás a nadie te vas a ir en una silla de ruedas". Ahí conocí lo que era la picana, lo que era el submarino; estar siete días encerrada comiendo polenta con cucarachas. Eso fue en Jefatura (Entrevista a Dinorah).

${ }^{16}$ Ladrones. 
A María una vez al llegar detenida a Jefatura le preguntaron a quién tenían que avisarle en caso de muerte.

-Más de una vez me pusieron capucha y me picanearon. Te pedían nombres, te pegaban...

- ¿Nombres de quién?

-De gente que andaba robando. Una vez me acuerdo que había gente que andaba robando los focos de luz de la calle y querían que les dijéramos quiénes eran (Entrevista a María).

Además, le hicieron un simulacro de fusilamiento y varias veces submarino:

Te hacían el submarino con una bolsa, te ponían la bolsa y te asfixiaban (Entrevista a María).

Querían saber nombres de pungas ${ }^{17}$, de tipos que andaban robando. Ellos pensaban que nosotros andábamos con ellos (Entrevista a Alejandra).

No resulta fácil entender las razones por las que los policías asociaban a las travestis con el mundo del delito. Sus clientes no necesariamente eran delincuentes, y si lo eran no era con ellas con quienes compartían los detalles de sus actividades, en todo caso contratarían sus servicios y el vínculo terminaba ahí. Una posible explicación tiene que ver con que asociaban a las travestis con un "submundo" donde los delincuentes también se movían.

Varias hicieron referencia a las condiciones adentro de las comisarías y de Jefatura:

Si estabas en el patio grande dormíamos una apretada con la otra. En los calabozos muchas veces nos tenían desnudas (Entrevista a Elisa).

En los calabozos era común que nos tuvieran desnudas o con poca ropa. A veces lograbas conseguir una frazada (Entrevista a Verónica).

Desnudarte y ponerte con las manos arriba, y tirarte agua en pleno invierno (Entrevista a Alejandra).

El hecho de darte empujones, cachetadas, maltratarte, eso no era nada para la policía, era una cosa rutinaria. Nosotras no protestábamos por el miedo que teníamos (Entrevista a Elisa).

Me pasó de estar durmiendo en el calabozo y de atrás de la reja un milico te hacía pichí encima, y te decía: "Ay me equivoqué de baño" (Entrevista a Alejandra).

No nos daban comida ni agua ni abrigo. A veces algún policía nos alcanzaba (Entrevista a María).

A veces te habían llevado [detenida] la noche anterior y pensabas que esta noche no te iban a llevar, y te veían y te llevaban de nuevo los mismos (Entrevista a Alejandra).

\footnotetext{
${ }^{17}$ Carteristas o ladrones que operan por descuido de la víctima.
} 
Las detenciones no sólo se hacían en la calle, también las iban a buscar a los domicilios:

Nos venían a buscar de madrugada, a cualquier hora... A veces nos íbamos a dormir a la azotea porque así no nos encontraban (Entrevista a María).

Me acuerdo que nos escondíamos en la pensión, poníamos candado para que no nos sacaran. (Entrevista a Dinorah).

Yo estaba en la pensión y me tiraban la puerta abajo. Entraban y me decían "vení" (Entrevista a Alejandra).

\section{Trabajos forzados}

En algunos testimonios se encuentran referencias a la realización de trabajos forzados estando detenidas. El no hacerlos implicaba mayor tiempo en la detención o un incremento en los rigores de la misma, por ejemplo, no proporcionarles comida ni agua.

Nos hacían barrer y baldear la comisaría, sino no nos dejaban ir (Entrevista a Verónica).

Nos decían: “¿Quieren irse? Bueno hagan fajina ${ }^{18 ”, ~(E n t r e v i s t a ~ a ~ M a r i ́ a) . ~}$

Esos "trabajos" a los que varios testimonios hacen referencia incluso trascendían la órbita de la comisaría o de Jefatura y en ocasiones podían realizarse afuera:

Cuando estaba por venir la Rural del Prado ${ }^{19}$, nos llevaban a varias trans a limpiar los galpones, y cuando terminaba también (Entrevista a María).

En el último año de la dictadura algunas también fueron obligadas a borrar las huellas de la represión.

Nos ponían a romper papeles, fichas de la gente, que quedábamos con los dedos duros. Dos horas rompiendo papeles y salíamos. [...] Por esa época nos tenían menos tiempo, veinticuatro horas, y nos llevaban a un lugar donde había galpones y nos ponían a romper fichas de la gente, con foto. (Entrevista a María).

En este relato se ilustra claramente el carácter de no-persona que el régimen le asignaba a estas mujeres, aun en los meses finales de la dictadura. No sólo en su pasaje por los calabozos habían sido abusadas y violentadas, también habían sido testigos de que eso se hacía con otras personas. Como otras veces se las había obligado a limpiar las comisarías, ahora tenían que "limpiar" las pruebas, los "documentos de barbarie". Esa tarea solo podría ser encargada a alguien que no

\footnotetext{
${ }^{18}$ Se refiere a hacer la limpieza.

${ }^{19}$ Se trata de una exposición agroindustrial que se realiza cada año en la ciudad de Montevideo.
} 
tuviera las credenciales suficientes para ser escuchada, para hacer valer su testimonio. No importaba lo que habían pasado ni lo que supieran, porque no tenían "voz", ni tampoco tenían capacidad de interactuar con quienes sí podrían hacer valer su voz (por ejemplo, los organismos de derechos humanos). Además, esto también muestra que, en la lógica de los represores, ese carácter de no-persona trascendía el alcance del propio régimen. No se trataba de algo impuesto a un conjunto de sujetos por una decisión cuyo efecto caería una vez que los militares se retiraran del poder. Una vez finalizada la dictadura tampoco tendrían capacidad de ser escuchadas, porque su incapacidad de enunciación no era un producto del régimen, era una propiedad inherente a esos sujetos.

\section{Ocupar y evitar el espacio público}

Un efecto de la dictadura fue el abandono del espacio público para refugiarse en el ámbito privado. Esa fue una de las formas que asumió la resistencia. La vigilancia extrema y la delación estaban a la orden del día. Hablar en el ómnibus, conversar en el almacén, implicaba un cierto riesgo incluso para quienes estaban fuera de la militancia política. En un régimen donde delatar podía ser un medio para adquirir estatus, cualquier vecino era un potencial delator. El efecto entonces era obvio; mejor guardarse cualquier opinión por banal que fuera, mejor resguardarse en el hogar que salir al espacio público; mejor pasar desapercibido que llamar la atención.

Un motivo de indagación del presente trabajo fue conocer las formas en que las mujeres trans sobrellevaron este aspecto. ¿Cómo "salir" del espacio público cuando el trabajo sexual era su principal medio de vida e implicaba justamente "ocupar" ese espacio? ¿Cómo "circunscribirse” al ámbito privado cuando su exterioridad, su imagen, inevitablemente las marcaba, las hacía destacarse?

Si como dice Henri Lefebvre -citado por Manuel Delgado- "toda práctica social practica el espacio, lo produce, lo organiza, y sólo puede hacerlo a través de esa herramienta con que sus componentes cuentan y que es el cuerpo" (Delgado, 2006:113); hay ahí una disputa de las travestis por la producción del espacio. Cuando había un "repliegue" generalizado de la ciudadanía hacia lo privado, hubo sectores que no tuvieron otra alternativa para subsistir que seguir resistiendo por la ocupación del espacio público, encontrando formas de minimizar los riesgos, de ser visibles para unos y no para otros. 
Estar en la parada era estar siempre alerta, calibrando en qué momento mostrarse y en qué momento ocultarse. Ese continuo despliegue y repliegue de los cuerpos travestidos fue la estrategia de las trabajadoras sexuales en calle; ser visibles y alcanzables para unos (clientes) y ser invisibles e inalcanzables para otros (represores).

Esto no sólo dependía de cada persona. En la parada se daban distintas formas de solidaridad entre las travestis para protegerse: se avisaban con gritos y silbidos si andaba la policía; y también había clientes, automovilistas, tacheros (conductores de taxis), transeúntes y vecinos algunos que no conocían- que les avisaban si andaba la policía cerca.

De este modo, la posibilidad de habitar el espacio público dependía de varios factores, no sólo de la capacidad de cada una para evadir la represión, también de la solidaridad de las compañeras y de otras personas, y por supuesto que el factor suerte también era fundamental.

Por fuera de las horas dedicadas al trabajo sexual, para estas mujeres estar travestidas en el espacio público también era muy riesgoso por lo que debían desarrollar estrategias para minimizar su exposición.

Yo iba vestida de varón [a trabajar] y me llevaba la ropa en un bolso. Me cambiaba en el jardín de una casa. Si ibas vestida de mujer lo más probable era que no llegaras a la esquina (Entrevista a Adriana).

Muchas de las trans que vivíamos en aquella época durante el día teníamos que vestirnos de hombres [...] Muchas de las chicas que íbamos a Bulevar o a Propios nos cambiábamos en los jardines (de las casas). Y ahí nos maquillábamos un poquito, así nomás (Entrevista a Dinorah).

Nosotras nos juntábamos entre dos o tres y nos íbamos en taxi a Bulevar [...] Si iba por ejemplo una rubia, la hacíamos sentar atrás, porque si iba adelante llamaba la atención y los milicos paraban el taxi. Más de una vez nos pasó eso, paraban el taxi y te llevaban (Entrevista a Verónica).

Se encontraban formas, se iban "haciendo rutinas" para reducir el riesgo:

Si ibas al centro, a comprarte algo a una galería, tenías que bajarte en la puerta en un taxi y volverte en taxi. Si la policía te veía de día te paraba (Entrevista a Verónica).

Si ibas a un bar te sentabas lejos de la puerta y lejos de la ventana. Si te veían te sacaban (Entrevista a Celia).

Le pagaba a una vecina para que me hiciera las compras (Entrevista a Celia).

Les pagaba a unas chiquilinas y ellas iban al almacén (Entrevista a Alejandra). 


\begin{abstract}
Abusos sexuales
Todas las entrevistadas sufrieron distintas formas de abuso sexual por parte de policías y en algunos casos también por parte de militares. Las violaciones eran algo con lo que cotidianamente tenían que lidiar en ese período. Estaban plenamente legitimadas en el accionar represivo, contaban con el aval de los jerarcas e incluso se disponían espacios con "mayor intimidad" en las comisarías para poder realizarlas.

En cada comisaría había un cogedero (Entrevista a María).

Te llevaban a una sala y ahí tenías que tener relaciones (Entrevista a Verónica).

A veces te hacían subir al patrullero para que se la chupes (Entrevista a Elisa).

En los camiones a veces te violaban, arriba de los camiones (Entrevista a Alejandra).
\end{abstract}

Otras veces se utilizaba como un chantaje para otorgar la libertad:

Para salir tenías que acostarte con los policías, era "como" una violación, o tenías que hacer la fajina de limpiar los calabozos (Entrevista a Elisa).

El "como" de esa frase de Elisa puede referir al hecho de que, tal como ella lo formula -que es como lo formulaban los policías- se daba a entender que había un consentimiento, que había un margen para decir que no. Pero a pesar de la forma en que los represores lo expresaban, no había mucha posibilidad de negarse, las sanciones no habilitaban ese margen. Pero puede entenderse de otras maneras que no necesariamente son excluyentes: como una forma de tomar distancia de todo lo que connota una violación, del dolor que implica haberla vivido y tener que decirlo con la crudeza de las palabras, y también se puede explicar por el efecto de la despersonalización en las mujeres trans: se viola a una persona, no a una trans; el "acceso" a los cuerpos de estas últimas no tenía la misma entidad que en otros cuerpos.

Rita Segato establece la distinción entre la concepción premoderna y moderna de la violación. En el primer caso, la violación no es un acto contra una mujer, es una cuestión de Estado, un asunto de soberanía territorial, en tanto la mujer es un patrimonio, un bien de algunos hombres a quienes se les ocasiona un daño por transitiva. En el segundo caso, en tanto existe una noción de ciudadanía e individualidad, la violación es una agresión contra la mujer y recién entonces se 
configura como un delito. Esta distinción no es excluyente, la autora demuestra la persistencia en la legislación brasileña de componentes premodernos para considerar la violación, por ejemplo, cuando se la califica como una afrenta contra las "costumbres". En ese caso no se apunta al daño producido a la mujer, sino que se condena el daño producido a la comunidad y al orden social (Segato, 2010:26-27).

Tomando en consideración esta distinción, interesa analizar si es pertinente para el caso de la violación de mujeres trans bajo el terrorismo de Estado. Cómo concebir la violación de quienes no poseían el estatus de persona. En qué medida la violación por parte de los represores vehiculizaba un componente punitivo y disciplinario. No se hacía como un medio para doblegar a la víctima y obtener información. Se hacía sobre cuerpos que habían sido despojados de su condición humana. No existía ningún interés en sancionar su comportamiento y mucho menos en "reencauzarlo" a través del disciplinamiento. Tampoco parecía existir una intención expresa de imponer la disciplina a terceras personas a través de lo que debían atravesar quienes se apartaban de "lo natural".

Las travestis constituían un stock de las comisarías. El fichaje permitía localizarlas y abusar de ellas a discreción. El acceso a sus cuerpos constituía uno de los "premios" del trabajo represivo, incluso la posibilidad de disponer de un "momento de distensión" en medio de la jornada laboral, e incluso fuera de ella.

En el informe del Servicio Paz y Justicia se cita una carta enviada por un militar a Amnistía Internacional en 1976:

Las mujeres son un tema aparte: los oficiales, suboficiales y la tropa comentan con regocijo la llegada de detenidas jóvenes. Algunos de éstos han llegado a venir los días francos para participar en los interrogatorios (Serpaj, 1989).

Algunos testimonios de personas detenidas por su militancia política narran que muchas veces eran recibidos con golpizas en Jefatura, en las que incluso participaban funcionarios administrativos que no se privaban del "goce" de propinar golpes a los recién llegados. También hay testimonios que relatan la presencia de policías y militares que en sus días libres y fuera de su horario de trabajo, permanecían en las unidades para participar de estos abusos. 
Pero esta violencia dirigida a militantes políticos y sociales, más allá de los móviles individuales de los agresores, tenía un objetivo claro de doblegarlos, hacerlos que colaboren en brindar información, hacerlos desistir -a ellos y a sus colegas- de continuar en la militancia.

En el caso de las mujeres trans la violencia dirigida hacia ellas no tenía esa intencionalidad. No era información lo que se buscaba -si bien en los testimonios se relatan torturas para obtener nombres de personas vinculadas al delito-ni tampoco hacerlas desistir de la vida que llevaban.

Podía ser generar cohesión dentro de los propios represores. Participar de los mismos abusos generaba vínculos entre los propios policías y militares, y también significaba un indicador de hasta dónde estaba dispuesto a llegar cada uno.

\section{Conclusión}

En el texto se demuestra que durante el período de la dictadura cívico-militar uruguaya se ejerció desde el Estado una violencia cotidiana hacia mujeres trans que realizaron trabajo sexual en calle. Esa violencia asumió la forma de detenciones, fichajes, hostigamientos, violaciones, torturas y trabajos forzados. La violencia de que fueron objeto las mujeres trans durante en ese período no fue parte de un "exceso" del accionar represivo, ni tampoco fue igual que con otros sectores, sino que adquirió características específicas. Si bien el Estado tradicionalmente ejerce formas de violencia heteronormativa, durante ese período la misma se agravó al ligarse con ideas de peligrosidad social y sobre el mundo delictivo donde se entendía que circulaba y operaba la disidencia sexual.

A partir de los relatos que se reúnen en este trabajo se permite entender que esas mujeres trans que realizaban trabajo sexual en calle no eran consideradas personas por el régimen. La violencia dirigida contra ellas no tenía por efecto exterminarlas, pero sí controlarlas, limitar su presencia en el espacio público, y asignarles un lugar marginado en la sociedad en tanto eran consideradas una aberración y un riesgo para la sociedad.

Así como el régimen construyó su imagen del ciudadano ideal, poseedor de los valores esenciales de la nación y con el desafío histórico de refundar el país, también construyó su antítesis en la figura del "subversivo". En esa dicotomía, las mujeres trans no encontraron un lugar, no tenían ningún rol que el régimen les atribuyera, su existencia estaba por fuera de este esquema. La 
construcción que se hacía de ellas era principalmente de índole moral. Como tampoco encontraron un lugar en la "cultura de la impunidad" (Rodríguez, 2011) que se impuso tras la apertura democrática, ya que su sustento basado en la "teoría de los dos demonios" ${ }^{20}$ no habilitaba ningún margen para ubicar a la represión sobre la disidencia sexual durante la dictadura. ¿En qué medida las mujeres trans se podían equiparar a uno de esos demonios? ¿Contra quién estaban en guerra? No es casualidad que toda referencia a la violencia contra la diversidad sexual haya permanecido silenciada por la impunidad instalada tras la salida de la dictadura, su visibilidad podía implicar erosionar su base de sustento.

La verdadera dimensión de la dictadura se puede entender, más allá de la violencia con que persiguió a quienes consideraba como enemigos políticos, en el desprecio con que consideró y trató a quienes estaban en situación de mayor vulnerabilidad y que no sostenían un "proyecto político" pero que constituían una amenaza para el régimen por el propio hecho de su existencia. $\mathrm{Y}$ en gran medida ese desprecio continuó en gobiernos posteriores a la dictadura, donde la democracia "tutelada" para la mayoría se constituyó para algunos sectores minoritarios en una democracia "negada".

Los relatos de estas mujeres interpelan en varios sentidos. Ser víctimas en la dictadura no fue algo raro: diversos grupos sociales lo fueron; la represión operó a gran escala y dejó sus efectos en amplios sectores de la sociedad. Pero la forma en que operó la represión sobre los diferentes sectores sociales adquiere en algunos casos componentes específicos que es necesario analizar. La represión, por sus propias acciones o por la forma en que generó resistencias, tuvo una centralidad en la construcción de subjetividades. Al volverse parte de la cotidianidad de algunos sectores sociales, el vínculo con las "fuerzas del orden" fue en cierto modo constituyente de algunas identidades. En el caso que aquí analizamos, hacerse trans/travesti era vestirse con ropas de mujer, era feminizarse el cuerpo, era hacer la calle, era ser objeto de discriminación de vecinos e instituciones, era también ser detenida y violentada en una comisaría, era desarrollar estrategias para minimizar el efecto de esto. Esa cotidianidad devino en muchos casos en una naturalización que en parte explica que la violencia sufrida por este colectivo durante tanto

\footnotetext{
${ }^{20}$ La "teoría de los dos demonios" es una concepción que prevaleció en Argentina y Uruguay que equipara la violencia ejercida por las organizaciones guerrilleras con la violencia del terrorismo de Estado. De este modo, la sociedad fue víctima de la guerra entre esos "demonios" y de los excesos que cometieron.
} 
tiempo no haya salido a luz hasta años recientes y continúe siendo una de las tantas cuestiones irresueltas de la democracia. En octubre de 2018 se aprobó la Ley Integral para Personas Trans ${ }^{21}$ que incluye un reconocimiento por parte del Estado de la violencia que ejerció en el pasado sobre las identidades trans y establece una acción reparatoria. La iniciativa partió de un grupo de mujeres trans veteranas que en 2016 exigieron una respuesta del Estado por la violencia que ejerció contra ellas en el pasado. Los caminos de la memoria y sus potencialidades políticas aún están abiertos, y este texto pretender ser una contribución en ese sentido.

${ }^{21}$ Disponible en https://www.impo.com.uy/bases/leyes/19684-2018 (Consultado 2/10/2019). 


\section{Referencias}

Agamben, G. (2010). Homo sacer. El poder soberano y la nuda vida. Valencia: Pre-Textos.

Caetano, G. (2016). La vida política. En G. Caetano, A. Marchesi, V. Markarian y J. Yaffé (Eds.), Uruguay. En busca del desarrollo entre el autoritarismo y la democracia. Tomo III (pp. 37-111). Montevideo: Editorial Planeta.

Caetano, G. y Rilla, J. (2017). Breve historia de la dictadura (5a ed.). Montevideo: Ediciones de la Banda Oriental.

Calvo Núñez, M. (2013). Contra viento y marea: La vejez y las identidades que aun sin poder ser, fueron. En D. Sempol (Ed.), Políticas públicas y diversidad sexual. Análisis de la heteronormatividad en la vida de las personas y las instituciones. Informe final (pp. 129-163). Montevideo: Ministerio de Desarrollo Social.

Calvo Núñez, M. (2017). Huellas de represión y resistencia. Vivencias desde los cuerpos silenciados. Seminário Internacional Fazendo Gênero 11 y 13th Women's Worlds Congress (Anais Eletrônicos), Florianópolis.

Carvajal, F. (2019). Pasados suspendidos. Estrategias represivas y tecnologías biopolíticas sobre las disidencias sexogenéricas durante la dictadura de Augusto Pinochet en Chile. Páginas, 11 (27).

Cutuli, M. S. e Insausti, S. J. (2015). Cabarets, corsos y teatros de revista: espacios de transgresión y celebración en la memoria marica. En J. L. Peralta y R. M. Mérida Jiménez (Eds.), Memorias, identidades y experiencias trans. (In)visibilidades entre Argentina y España (pp. 1939). Buenos Aires: Editorial Biblos.

D’Antonio, D. (Ed.) (2015). Deseo y represión. Sexualidad, género y Estado en la historia argentina reciente. Buenos Aires: Imago Mundi.

Delgado, M. (2006). Tránsitos. Espacio público, masas corpóreas. En A. Ortiz-Osés y P. Lanceros (Eds.), La interpretación del mundo. Cuestiones para el tercer milenio (pp. 113-131). Barcelona: Anthropos.

Fernández, J. (2004). Cuerpos desobedientes. Travestismo e identidad de género. Buenos Aires: Edhasa.

Gómez Sóñora, V. (2016). Vivir dignamente: trayectorias en el marco de la Ley "Derecho a la Identidad de Género y al cambio de nombre y sexo en documentos identificatorios". Tesis de grado. Facultad de Humanidades y Ciencias de la Educación, Universidad de la República, Montevideo.

Green, J. N. y Quinalha, R. (Eds.) (2014). Ditadura e homossexualidades. Repressão, resistência e a busca da verdade. São Carlos: EdUFScar.

Greising, C., Pérez, C., Rostan, E. y Silva Schultze, M. (2011). Historia Uruguaya 11. La Dictadura 1973-1984. Montevideo: Ediciones de la Banda Oriental. 
Gutiérrez Nicola, G. (2018). "Éramos trans, no éramos delincuentes". Terrorismo de Estado y violencia estatal hacia mujeres trans en Uruguay (1973-1985). Tesis de grado. Facultad de Humanidades y Ciencias de la Educación, Universidad de la República, Montevideo.

Insausti, S. J. (2015). Los cuatrocientos homosexuales desaparecidos: memorias de la represión estatal a las sexualidades disidentes en Argentina. En D. D'Antonio (Ed.), Deseo y represión. Sexualidad, género y Estado en la historia argentina reciente (pp. 63-82). Buenos Aires: Imago Mundi.

Mauros, R. (2017). Vejeces subversivas: Identidades trans y su relación con los procesos de envejecimiento. Tesis de grado. Facultad de Ciencias Sociales, Universidad de la República, Montevideo.

Micieli, C. y Pelazas, M. (2017). Ser nacional y tanatopolítica. Buenos Aires: La Parte Maldita.

Peralta, J. L. y Mérida Jiménez, R. M. (Eds.) (2015). Memorias, identidades y experiencias trans. (In)visibilidades entre Argentina y España. Buenos Aires: Editorial Biblos.

Pelúcio, L. (2005). Na noite nem todos os gatos são pardos. Notas sobre a prostituição travesti. Cadernos Pagu, (25), pp. 217-248.

Perlongher, N. (2018). El negocio del deseo. Una cartografía de la prostitución masculina. Buenos Aires: Azafrán.

Rico, A. (2013). Sobre el autoritarismo y el golpe de Estado. La dictadura y el dictador. En C. Demasi, A. Marchesi, V. Markarian, A. Rico y J. Yaffé (Eds.), La dictadura cívico-militar. Uruguay 1973-1985 (pp. 179-246). Montevideo: Ediciones de la Banda Oriental.

Rodríguez, R. (2011). Sinlogismos de impunidad. Intervención en la Mesa redonda y debate "Cultura de la impunidad". Conferencia en San Carlos, Maldonado. Recuperado a partir de http://www.surysur.net/uruguay-sinlogismos-de-impunidad/ (Consultado 10/2/2018).

Segato, R. L. (2010). Las estructuras elementales de la violencia. Buenos Aires: Prometeo Libros.

Sempol, D. (2013). De los baños a la calle. Historia del movimiento lésbico, gay, trans uruguayo (1984-2015). Montevideo: Sudamericana.

Sempol, D. (2015). Autoritarismos morais, dissidência sexual e memória: ditaduras civil-militares na Argentina e no Uruguai e organizações LGTTBIQ. En S. Viz Quadrat y D. Rollemberg (Eds.), História e memória das ditaduras do século XX (Vol. 2, pp. 163-200). Rio de Janeiro: Editora FGV.

Sempol, D. (2018). Homosexual: entre el insulto y el orgullo. Políticas de la Memoria (18), pp. 222-234.

Sempol, D. (2019). Memorias trans y violencia estatal. La Ley Integral para Personas Trans y los debates sobre el pasado reciente en Uruguay. Páginas, 11 (27). 
Sempol, D. y Graña, F. (2011). Salvar a la patria y a la familia. Dictadura, disidencia sexual y silencio. En S. González Baica y M. Risso Fernández (Eds.), Las Laurencias. Violencia sexual y de género en el terrorismo de Estado uruguayo (pp. 85-103). Montevideo: Ediciones Trilce.

Serpaj (1989). Uruguay nunca más: informe sobre la violación a los derechos humanos (19721985). Montevideo: Servicio Paz y Justicia. 